\title{
Alguns aspectos metodológicos em História da Geografia e Geografia Histórica
}

Relato de pesquisa sobre o Ministério do Interior no Brasil

Algunos aspectos metodológicos en Historia de la Geografía y Geografía

Histórica: informe sobre una investigación acerca del Ministerio do Interior de

Brasil

Some methodological aspects in history of Geography and historical Geography: research report on the Ministério do Interior in Brazil

Quelques aspects méthodologiques dans l'histoire de la géographie et la géographie historique: rapport de recherche sur le Ministério do Interior au Brésil.

\section{Gustavo Soares lorio}

\section{OpenEdition}

\section{Journals}

Edição electrónica

URL: https://journals.openedition.org/terrabrasilis/2419

DOI: 10.4000/terrabrasilis. 2419

ISSN: 2316-7793

Editora

Rede Brasileira de História da Geografia e Geografia Histórica

Refêrencia eletrónica

Gustavo Soares Iorio, «Alguns aspectos metodológicos em História da Geografia e Geografia Histórica», Terra Brasilis [Online], 9 | 2017, posto online no dia 31 dezembro 2017, consultado o 05 dezembro 2022. URL: http://journals.openedition.org/terrabrasilis/2419 ; DOI: https://doi.org/10.4000/ terrabrasilis. 2419

Este documento foi criado de forma automática no dia 5 dezembro 2022

All rights reserved 


\section{Alguns aspectos metodológicos em História da Geografia e Geografia Histórica}

Relato de pesquisa sobre o Ministério do Interior no Brasil

Algunos aspectos metodológicos en Historia de la Geografía y Geografía

Histórica: informe sobre una investigación acerca del Ministerio do Interior de

Brasil

Some methodological aspects in history of Geography and historical Geography: research report on the Ministério do Interior in Brazil

Quelques aspects méthodologiques dans l'histoire de la géographie et la géographie historique: rapport de recherche sur le Ministério do Interior au

Brésil.

\section{Gustavo Soares Iorio}

\section{Introdução}

10 presente texto é um relato de pesquisa realizada como tese de doutoramento no âmbito no Programa de Pós Graduação em Geografia da Universidade Federal do Rio de Janeiro (PPGG), defendida em 2015. ${ }^{1}$ Mais do que apresentar as análises efetivamente desenvolvidas na tese, aproveito este para discutir alguns aspectos de ordem metodológica na construção e desenvolvimento da pesquisa.

Interessa-me, sobretudo, abordar duas questões: $i$ ) a relação entre a história da geografia e geografia histórica do ponto de vista da abordagem analítica, i.e., a metodologia; ii) a escolha e o tratamento das fontes. 0 artigo está dividido em três partes. Para contextualizar o leitor, começo com uma pequena apresentação sobre o objeto de estudos adotado na pesquisa: o Ministério do Interior (MINTER); em seguida discuto a abordagem a partir da História da Geografia e da Geografia Histórica; na 
terceira parte reflito sobre o percurso de pesquisa no Arquivo; encerro com algumas considerações finais.

\section{Sobre o ministério do interior}

Formalmente criado pelo Decreto-Lei ํㅡㄴ 200 de fevereiro de 1967, a gênese do MINTER remonta a 1964, nos primeiros momentos de implantação do regime militar, quando em 21 de junho de 1964 foi criado o cargo de Ministro extraordinário através da Lei nº 4344 (Brasil, 1964a), que passa a ser Ministério Extraordinário para a Coordenação dos Organismos Regionais (MECOR) através da Lei no 54026 de 17 de julho de 1964 (Brasil, 1964b). Basicamente, o ministério extraordinário assumia para si onze órgãos agrupados em torno da alcunha "organismos regionais", ${ }^{2}$ que refletiam contextos e finalidades distintos, às vezes até contraditórios (Iorio, 2015).

O MECOR torna-se MINTER através da Reforma Administrativa desenhada pelo DecretoLei no 200/1967 (Brasil, 1967), inserido no rol denominado "Setor econômico". No entanto, o desenho administrativo do ministério só ganhou formato mais definitivo através do Decreto 66.882/1970 (Brasil, 1970):

Art. $2^{\circ} \mathrm{A}$ estrutura básica do Ministério do Interior compreende os seguintes órgãos da administração direta:

I - Órgãos de assistência direta e imediata ao Ministro:

a) Gabinete

b) Consultoria Jurídica

c) Divisão de Segurança e Informações

II - Órgãos Centrais de planejamento, coordenação e contrôle [sic] financeiro:

a) Secretária Geral

b) Inspetoria Geral de Finanças

III - Órgão Central de direção superior:

a) Departamento de Administração

\& $1^{\circ}$ São vinculadas ao Ministério do Interior as seguintes entidades da administração indireta:

I - Entidades de coordenação e planejamento regional:

a) Superintendência do Desenvolvimento da Amazônia - SUDAM;

b) Superintendência do Desenvolvimento do Nordeste - SUDENE;

c) Superintendência do Desenvolvimento da Região Centro-Oeste - SUDECO;

d) Superintendência do Desenvolvimento da Região Sul - SUDESUL;

II - Entidades de desenvolvimento sub-regional:

a) Superintendência da Zona Franca de Manaus - SUFRAMA;

b) Superintendência do Vale do São Francisco - SUVALE;

c) Departamento Nacional de Obras Contra as Sêcas - DNOCS;

III - Entidades relacionadas com o desenvolvimento urbano e local integrado e a melhoria das condições do meio ambiente:

a) Banco Nacional de Habitação - BNH;

b) Serviço Federal de Habitação e Urbanismo - SERFHAU;

c) Departamento Nacional de Obras de Saneamento - DNOS.

IV - Entidades regionais e sub-regionais de financiamento:

a) Banco da Amazônia S.A. - BASA;

b) Banco do Nordeste S.A. - BNB; 
c) Banco de Roraima S.A.

$\mathrm{V}$ - Entidade de integração sócio-econômica ao processo de desenvolvimento:

a) Fundação Nacional do Índio - FUNAI.

$\S 2^{\circ}$ Os Territórios Federais, unidades descentralizadas da Administração Federal, a nível sub-regional, com autonomia administrativa e financeira, equiparados, para os efeitos legais, às entidades da administração indireta, são vinculados ao Ministério do Interior para os fins de supervisão ministerial de que tratam o Decreto-lei ํํ르 200, de 25 de fevereiro de 1967, e as demais leis e regulamentos pertinentes ao assunto.

5 As diferenças entre os textos de 1964 e de 1970 são sensíveis. Trata-se de mudanças substanciais, muito mais do que mera nomenclatura. O texto de 1970 apresenta um arranjo institucional muito mais coerente e coordenado de entidades, que se uniformizam no que tange a modos de operação e metas a atingir. O desenvolvimento se torna o caráter central desse ministério, suprimi qualquer ambiguidade; fato visível pela proliferação de superintendências de desenvolvimento justapostas aos bancos regionais. ${ }^{3}$

O caráter e o sentido do MINTER ao longo de toda sua trajetória são definidos em seus aspectos estruturais neste intervalo entre 1964 e 1970, doravante chamado de fase de institucionalização. Neste período estiveram à frente do ministério o mal. Cordeiro de Farias e o gal. Albuquerque Lima, este é o intervalo temporal da análise desenvolvida na tese.

\section{O Ministério do Interior, a História da Geografia e a Geografia Histórica}

7 O primeiro, digamos assim, "paradoxo metodológico" com que me deparei nesta pesquisa foi: $i$ ) tomar o MINTER enquanto uma instituição do pensamento geográfico $\mathrm{e}$ assim investiga-lo como portador/reprodutor de representações sobre o Brasil; ou, ii) por outra feita, assumi-lo como agente de formação territorial, ou seja, assumindo o ponto de vista da Geografia Histórica. Estava, portanto, entre uma dicotomia de difícil solução: optar pela dimensão simbólica ou pela material. A solução era difícil porque à medida em que aprofundava a análise e aproximava-me da documentação a distinção entre um e outro parecia impossível.

8 Convenci-me de que a distinção proposta era irrealizável. 0 discurso geográfico ${ }^{4}$ sobre a ordem espacial, a composição intelectual de nexos articulando as formas e os conteúdos espaciais (Gomes, 2006) prescreve e orienta ações objetivas nas formações sociais, inclusive nos próprios processos de territorialização (ou produção do espaço), ao que David Harvey (1990), chamaria de estudo das representações geográficas como parte do movimento geral de reprodução social.

Os discursos sobre o território convergem com a formação territorial em si, implicando, do ponto de vista analítico, que os estudos de história da geografia se encontrem com aqueles da geografia histórica (Zusman, 2000). Essa confluência destacou o papel das práticas, sujeitos e instituições que protagonizam a construção da representação geográfica do mundo, manifestadas nas formações territoriais de fato. ${ }^{5} \mathrm{~A}$ formação social brasileira passa pela constituição de seu território, e a formulação de um vasto e diversificado imaginário geográfico do país atravessa esse processo (Moraes, 2000). 0 discurso sobre a ordem espacial é parte da legitimação dos projetos territoriais: 
É possível que fique óbvio o fato de que, a certa formação territorial, deva proceder uma modalidade discursiva e um conteúdo substantivo e que, por intermédio de ambas, viabilize-se a legitimidade ideológica e a consecução prática daquele projeto que o construiu materialmente. (Escolar, 1996: 141)

10 A historiografia da geografia tem avançado na compreensão do significado de seus enunciados nas formações sociais concretas. Compreender as histórias da geografia através da análise de seus discursos concretos é uma tarefa empregada por Félix Driver (1992: 28) por meio da concepção segundo a qual as modalidades discursivas são práticas sociais situadas:

Ampliar o escopo da história crítica da geografia durante a era dos impérios poderia nos permitir considerar mais diretamente as dimensões culturais e políticas do conhecimento geográfico durante este período. Isto não é necessariamente abandonar uma abordagem materialista, o desenvolvimento do 'conhecimento' seria ao invés apreendido como uma prática social situada mais do que um reflexo espontâneo dos imperativos do desenvolvimento econômico. ${ }^{6}$

11 A meu ver, a concepção do discurso geográfico como prática social situada resume o que foi dito até aqui. Esta noção implica em reconhecer as modalidades discursivas em seus sentidos intencionais e relacionais, visualizar os sujeitos portadores e sua dinâmica íntima de produção. Este horizonte analítico também é apontado por Vincent Berdoulay (1981) em sua abordagem contextual. O contexto a qual se refere Berdoulay é mais objetivo do que aquele de que trata Harvey (op.cit.), não está focado majoritariamente na escala ampla (que para Harvey é a da reprodução do capital), atenta-se para questões mais palpáveis e bastante significativas. No foco da análise sobre a história da geografia estão aspectos de continuidade e descontinuidade de ideias; o resgate de "ideias vencidas", tendências significativas à época abordada que não podem ser negligenciadas; o contexto social mais amplo; os intercâmbios e debates de pensamento e, por fim, as razões que justificam o uso destas ou daquelas ideias.

12 As investigações derivadas desta perspectiva metodológica têm se afastado da busca pelos grandes sistemas teóricos no universo restrito das ideias, direcionando-se para os "pequenos usos" na História da Geografia. Por "pequenos usos" - na falta de expressão melhor - entenda-se os enunciados concretos, contextualizados, socialmente situados por agentes reais em circunstâncias empíricas da formação social e territorial. Esta abordagem historiográfica enriquece a análise da geografia histórica das formações sociais em si, e também fornecem um instrumental capaz de acessar a riqueza e a diversidade das ideias.

13 Por esta trilha a História da Geografia é enriquecida não só quando é posta ao lado da Geografia Histórica, mas também quando se dá conta das multiplicidades de sujeitos que reinventam as tradições do conhecimento, ofertando grande diversidade de discursos geográficos a serem investigados. Uma das linhas de investigações mais profícuas e instigantes que se abre é sobre o papel dos discursos geográficos como mediação no processo de formação dos Estados e das nações, tarefa que tem sido buscada pela historiografia da geografia brasileira.

14 O Estado se faz através das relações sociais que o compõem. A afirmativa parece óbvia, e de fato o é. Entretanto, é comum deparamos com certas análises que acabam por reproduzir uma visão reificada do Estado, reduzindo suas funções e os seus sentidos práticos a uma atitude pretensamente racional, apartada dos conflitos e dos jogos de poder presentes na chamada "sociedade civil". A concepção relacional do Estado o 
interpreta como objeto em disputa, cuja natureza só pode ser identificada em seu contexto social concreto.

Tomar o Estado como relações sociais implica também reconhecê-lo como objeto em movimento, ou, dito de outra forma, processo em formação. Por isso Antônio Carlos de Lima (1995), inspirado em Michel Foucault, prefere falar de processos de estatização ao invés de Estado. Os processos de estatização ocorrem através das disputas operadas no interior do campo político, ${ }^{7}$ mas também além dele. Envolvem-se nesse processo capitais simbólicos e econômicos. Tradições de conhecimento convertem-se em formas estatais. O dispositivo estatal é montado por processos de estatização, de diversas fontes sociais, em momentos históricos dispersos, e seu arranjo atual é a acomodação entre as heranças do passado e os imperativos do presente. A execução deste aparato, a maneira pela qual ela é exercida como mediação entre governo e aqueles definidos como objeto de sua ação (a "sociedade civil") é a governamentalização do Estado. ${ }^{8}$ Dito de outra forma, a governamentalização do Estado se faz em um complexo campo de disputas onde se define o objeto da ação, seus meios e suas metas.

O MINTER é uma prática de governamentalização do território, um mecanismo de ação cujo sentido pode ser buscado através de seu significado enquanto dispositivo dentro de campos de poder. Neste ponto se impõe uma questão escalar importante. Os campos de poder são objetivados por agentes sociais cuja ação remonta a níveis diferentes, p.ex.; empresas multinacionais, agências internacionais, órgãos governamentais nacionais, regionais, estaduais e municipais, técnicos e empresários locais, etc. Todos esses agentes se relacionam e através dessa relação forjam campos de poder. Para a compreensão desta unidade exige-se o reconhecimento de toda aquela multiplicidade, fato que impõe a consideração da escala como construção social objetiva. ${ }^{9}$

17 Ao analisar a prática de governamentalização do MINTER fica evidente que fatores de ordem diferente, mas interdependentes. são acionados. Na fase de institucionalização do ministério - contemplado nessa pesquisa - é perceptível que a montagem do desenho institucional do ministério responde a imperativos geopolíticos estreitamente relacionados ao movimento de mundialização do capitalismo, assim como questões específicas da formação social brasileira e também aspectos próprios dos sujeitos envolvidos e seus agrupamentos políticos mais diretos. A escala se aponta aí como a estrutura hierárquica no qual um processo se vincula ao outro, conformando relações de dependência entre os processos (Brenner, 2001).

O exemplo da institucionalização da prática de governamentalização do MINTER pode ser elucidativo. Ocorrido na segunda metade da década de 1960, ele enquadra-se perfeitamente no contexto da Guerra Fria no Brasil, no fortalecimento das empresas transnacionais. Por outro lado, se vertemos a mirada para a formação social e territorial brasileira, percebe-se que o mesmo ministério é caudatário de uma longa tradição de esforços no sentido de modernização do país e de seu território. Se, de outra feita, contempla-se o MINTER pelos seus ministros, Cordeiro de Farias e Albuquerque Lima, se nota uma visão do país marcada pelo peso de sua instituição profissional (o Exército brasileiro) e pelas suas relações pessoais e políticas particulares.

19 Em suma, as reflexões apontadas me levaram a tomar MINTER como i) um agente territorial na confluência entre História da Geografia e a Geografia Histórica; ii) constituído a partir de um processo dinâmico de formação do Estado e de sua governamentalização; iii) animado por sentidos que extrapolam as unidades escalares rigidamente recortadas. 
Neste processo não interessa investigar as consequências materiais estritamente - o que se fez e o que não se fez sobre o território - tampouco as grandes planificações, que revelam um conjunto articulado e abstrato de intenções. Preferi debruçar-me sobre o nível mais concreto da governamentalização, sem perder a dimensão do plano. Situei minha análise no imediato encontro entre a planificação e a execução, sem ser efetivamente nem um nem outro. Entendo esse encontro como a governamentalização em si, fato que se revela nos projetos de ação (Lima, 1995). Faltava-me ainda uma base documental que possibilitasse a análise.

\section{Sobre as fontes da pesquisa}

21 Meu contato com a documentação do MINTER vem da minha pesquisa de mestrado (Iorio, 2010), na qual tive que lidar com a documentação do MINTER depositada no Arquivo Nacional, sede de Brasília. No doutorado continuaria a utilizar a mesma base, agora disposto a examinar a prática de governamentalização do MINTER, o que exigiria uma busca bastante diferente de documentos.

As práticas de governamentalização não poderiam ser reduzidas à bases legislativas, aos pronunciamentos e discursos; ou às compilações de dados, números e estatísticas sobre ações e inversões. Seria necessária uma base documental que dê conta de revelar no cotidiano do ministério aspectos que fundamentam os modos de ver e conceber sua prática. Neste sentido a sugestão de Lima (1995: 96) é pertinente e enriquecedora para a análise sobre a administração pública.

Sua análise [da administração pública] não pode, porém, se resumir a um trabalho de arrolamento de leis e regulamentos administrativos, muitas vezes sem sequer declarar seu estatuto diferencial e limites de atribuição. Ainda que estes sejam matérias-primas importantes não se pode nem desprezá-los nem autonomizar o estudo do texto da lei, prescindindo-se de interpretá-los como peças de projetos de ação, cujo sentido só pode ser melhor apreendido em estudos que considerem também - mas não só - sua execução, perceptível através de investigações específicas.

Esta base documental está em geral depositada em instituições arquivísticas, responsáveis pela organização e disposição dos documentos, tarefas fundamentais que se refletem nas possibilidades de alcance das pesquisas. A pesquisa arquivística é uma maneira de "dar voz" a sujeitos históricos a partir daquilo que se quer compreender contemporaneamente; é uma reconstrução histórica que tem como fim inserir o passado no presente (Zusman, 2000). ${ }^{10}$ Há aí dois extremos: os sujeitos que produziram a documentação em suas práticas e o pesquisador que se dirige a essa documentação com perguntas que são dele, e não do sujeito primeiro. Há ainda um terceiro elemento que é a mediação entre os dois extremos, representada pela instituição arquivística, com seus procedimentos próprios, regidos por princípios técnicos adaptados às especificidades dos documentos geridos.

Vários encontros e desencontros resultam desta tripla incidência. Em primeiro lugar, o pesquisador procura por algo que não forçosamente foi formulado de maneira clara e objetiva pelo seu sujeito pesquisado, com isso, a resposta para o inquérito do investigador estará, provavelmente, disperso em documentos avulsos, e não em um documento pronto, definitivo e conclusivo. Em segundo lugar, o acesso a esses documentos dispersos se dará por intermédio dos critérios de organização escolhidos 
pelo arquivista; não necessariamente coincidentes com aqueles do sujeito e - menos provável ainda - com os do pesquisador. Os princípios de ordenação do arquivamento precisarão ser minimamente decifrados para facilitar o acesso àquilo que se busca.

Por todo este complexo percurso, os arquivos revelam aquilo que eles mostram e também o que não mostram. $O$ investigador precisa de zelo para não reproduzir acriticamente $i$ ) a intenção do sujeito, ao refletir justamente o que ele quis mostrar $\mathrm{e}$ silenciar sobre o que não foi pronunciado; ii) ou os princípios e conceitos do arquivista, que impôs (mesmo que de forma técnica, e não totalmente arbitrária) seus critérios de ordem sobre os documentos.

Este zelo, recomenda Antônio C. de Souza Lima (op.cit.), implica em que o pesquisador esteja munido de perguntas seguras, assentadas em critérios claros para que o objetivo da consulta logre êxito. Em função de a lógica de ordenação dos documentos serem alheias aos interesses de pesquisa, a clareza sobre aquilo que se busca auxilia o pesquisador a encontrar as trilhas dos documentos necessários para responder sua própria questão. Na medida em que vão se revelando os conteúdos dos documentos, outras questões relevantes surgem, o que parece enriquecedor para a análise; mas há que se ter sempre a precaução em não reproduzir princípios alheios à investigação.

Esses cuidados foram valiosos no enfrentamento da documentação do MINTER. Os primeiros contatos com o arquivo passaram a nítida impressão de que eu era um "geógrafo em terra estrangeira", tão inusitada me era a "situação de campo" em arquivo público. Lidar com arquivos é uma prática comum em outras disciplinas, daí decorre certa familiaridade com pesquisas documentais, estranha à formação de um geógrafo, ou mais particularmente à minha formação, em que não fui incitado a esta prática, muito menos à reflexão teórica sobre ela. De toda sorte, busquei nos arquivos por alguma base de documentos que revelasse a governamentalização praticada pelo MINTER a partir de sua lógica própria. Como estava intencionado em verter a análise para os projetos de ação, e não para as "grandes planificações" nem para o inventário de obras e gastos, me era necessário encontrar algo que estivesse no intermédio destes dois extremos. Busquei principalmente algo que pudesse ser organizado em sequências seriadas, algo que identificasse sistematicamente uma prática.

A documentação disponível estava organizada em uma base digitalizada, mas a consulta ao sistema de busca e aos documentos em si só pode ser efetuada na sede do Arquivo Nacional de Brasília. Esta base chegou ao Arquivo Nacional via Ministério do Planejamento, instituição responsável por organizar os documentos quando o MINTER foi extinto, em 1990. No sistema digital a busca se faz por entradas livres nas categorias: fundo, subfundo, grupo e subgrupo. Preenchi o fundo "Ministério do Interior" com praticamente todas as combinações possíveis entre as demais categorias. Desta busca deu-se uma primeira seleção de cerca de cinco mil documentos, a maioria deles examinei pelas ementas e outros tantos pelo documento físico. Fundamentalmente, estes documentos diziam respeito a pareceres jurídicos de projetos, anteprojetos de leis, convênios e parcerias com prefeituras (para construir obras, liberar recursos de assistência, projetos comunitários, etc.). Há também convênios com institutos de pesquisa, como o IBGE, esboços de regimentos dos órgãos subordinados, e coisas do gênero. Alguns documentos emitiam conteúdos que poderiam parecer mais substantivos, mas estavam sempre isolados, o que dificultou os contextualizar e, a partir daí, extrair qualquer significado. Além disso, esses documentos me forneciam uma visão muito parcial e fragmentada da prática de governamentalização do MINTER. 
Não encontrei ali qualquer possibilidade de seriação mais sistemática. Os documentos de mesma natureza tinham procedências diversas ou intervalos temporais muito longos.

Trabalhei com essa documentação por dois anos, tentando estruturar alguma base consistente e que me fornecesse conteúdos substantivos sobre a prática de governamentalização do MINTER. Estava com muitas dificuldades, e as possibilidades de se extrair elementos suficientes para realização da tese não eram animadoras; a discrepância entre os documentos disponíveis e os propósitos da pesquisa era gritante. Foram procurados relatórios ministeriais, atas de reuniões, cartas de ministros a seus superiores ou subordinados, ou qualquer outro material que indicasse os propósitos que orientaram a prática de governamentalização do MINTER. Entretanto, é flagrante a ausência de documentos de conteúdos mais substantivos. Segundo Torres (1989), o MINTER primou cuidadosamente da administração dos documentos produzidos, ${ }^{11}$ porém, o trabalho dela se refere à prática de documentação iniciada já no fim da década de 1970, quando já se passavam mais de dez anos de funcionamento desse ministério. De toda forma, mesmo considerando a documentação a partir deste período, a flagrante ausência de documentos com a natureza desejada permanece válida.

Esta me parecia uma situação incontornável, um empecilho difícil de superar e que comprometeria forçosamente o bom andamento de minhas pesquisas. Cheguei a crer que estes documentos poderiam não mais existir. Imaginei isso frente ao que prescreve o Decreto ํo 79.099 de 06 de janeiro de 1977, assinado pelo então presidente da República Ernesto Geisel e seu ministro da Justiça Armando Falcão. Este decreto trata da salvaguarda de assuntos sigilosos, sua tipologia e aplicação, na seção seis ("Destruição") do capítulo IV, intitulado "Documentos Sigilosos" a prática de destruição de documentos está prescrita da seguinte maneira:

Destruição

Art. 70. À autoridade que elabora documento ULTRA-SECRETO, SECRETO ou

CONFIDENCIAL, ou autoridade superior, compete julgar da conveniência da respectiva destruição e ordená-la oficialmente.

$\S 1^{\circ}$ Os documentos RESERVADOS não controlados serão destruídos por ordem da autoridade que os tenha sob custódia, desde que, perdida a oportunidade ou a utilidade, sejam por ela julgados desnecessários.

$\S 2^{\circ} \mathrm{A}$ autorização para destruir documentos sigilosos constará do seu registro.

Art. 71. Os documentos sigilosos serão destruídos pelo responsável por sua custódia, na presença de duas testemunhas.

Art. 72. Para a destruição de documentos ULTRA-SECRETOS e SECRETOS, bem como de CONFIDENCIAIS e RESERVADOS controlados, será lavrado um correspondente "Termo de Destruição", assinado pelo responsável por sua custódia e pelas testemunhas, o qual, após oficialmente transcrito no registro de documentos sigilosos, será remetido à autoridade que determinou a destruição e ou à repartição de controle interessada (Brasil, 1977).

32 Frente a este decreto, imaginei que os documentos que buscava poderiam ter sido objeto de destruição. Mesmo que tenha sido oficializado já no fim da década de 1970, quando já se tinham aí treze anos de funcionamento do MINTER (contando sua existência como MECOR), esse decreto revela uma prática oficial de destruição que poderia se imaginar vinha sendo adotada corriqueiramente. 
33 Em minha terceira visita ao arquivo, no último ano da pesquisa, em 2014, vivia-se um movimento de elevação dos ânimos em relação às pesquisas e investigações debruçadas sobre os arquivos do período do regime militar. Isto por duas razões principais: $i$ ) porque neste ano completou quarenta anos do golpe de 1964, reacendendo o assunto na opinião pública em geral; ii) em função do andamento dos trabalhos realizados pelo projeto "Memórias Reveladas".12 Este projeto, segundo a página "Histórico" de seu site, começou em 2005 através do Decreto no 5.584, que transferiu a guarda dos documentos do Conselho de Segurança Nacional (CSN) da Agência Brasileira de Inteligência (ABIN) para o Arquivo Nacional. Mas foi entre agosto de 2013 e março de 2014 que cerca de treze milhões destes documentos, depois de um longo processo, foram digitalizados. Esta digitalização facilitou a consulta aos documentos. Interesses acadêmicos, de pesquisa, ou pessoais, sobre perseguição, processos, etc., se voltaram para estes documentos. Minha pesquisa estava agora em um ambiente mais favorável.

Assim, nesta terceira visita, alguns pesquisadores do projeto trabalhavam no próprio prédio do Arquivo Nacional, em uma sala reservada ao lado da sala de consulta pública. ${ }^{13}$ Durante um dos intervalos da busca, em uma conversa despretensiosa com a funcionária do Arquivo que me atendeu ${ }^{14}$, falávamos sobre o trabalho desses pesquisadores e a questionei sobre a possibilidade deles encontrarem algo que poderia ser do meu interesse. Foi desta questão que avançamos a conversa sobre a base em que estava trabalhando, mencionei toda a dificuldade que estava encontrando e ela referiuse à existência de alguns documentos de naturezas diversas que estavam dispersos e depositados em outra base, oriundos de outra entrada, mas que havia a possibilidade de haver material do MINTER lá.

Esta base - doravante segunda base - (Arquivo Nacional, 2000) está organizada em dois grandes fichários (o conteúdo não está digitalizado) que elencam verbetes de entrada, agrupados em ordem crescente pelas caixas em que estão depositados os documentos $(1,2,3, \ldots)$. Não foi possível acessar qualquer pista sobre os critérios de ordenação das caixas. Segundo o guia de fundos do Arquivo Nacional, em sua página 23, o Fundo/ Coleção MINISTÉRIO DO INTERIOR foi organizado pela Coordenação de Documentos Escritos (CODES) e Coordenação de Documentos Audiovisuais e Cartográficos (CODAC) do Arquivo Nacional, e identificada pela Coordenação Regional do Arquivo Nacional no Distrito Federal (COREG). A consulta aí foi difícil, a organização dos arquivos é intrincada, os fichários acusavam entradas as mais diversas. Mas o universo documental contido nesta segunda base veio a ser, para os fins desta pesquisa, muito mais rico que o anterior. Aí foram encontrados registros a respeito das Comissões Coordenadoras do Ministério do Interior (CCMI), ${ }^{15}$ atas sobre propostas de reforma do ministério, entre outros tantos documentos que podem ser úteis às pesquisas de variados interesses, se houver paciência e persistência para situar-se no arquivo.

Deste universo variado, considerei como material mais valioso para o que estava buscando os cadernos com as Exposições de Motivos do MINTER. Segundo o Manual de Redação da Presidência da República (Brasil, 2002), em seu item 4:

Exposição de motivos é o expediente dirigido ao Presidente da República ou ao VicePresidente para:

a) informá-lo de determinado assunto;

b) propor alguma medida; ou

c) submeter a sua consideração projeto de ato normativo. 
Em regra, a exposição de motivos é dirigida ao Presidente da República por um Ministro de Estado.

Nos casos em que o assunto tratado envolva mais de um Ministério, a exposição de motivos deverá ser assinada por todos os Ministros envolvidos, sendo, por essa razão, chamada de interministerial.

Este foi um canal direto entre ministros e presidentes da República, através dele aqueles se apresentam em seus princípios a este. Matérias como: pedidos de revisão de orçamento, apresentação de anteprojetos de lei, movimentação de funcionários e tudo o mais que o ministro julgue relevante de ser comunicado, solicitado ou reclamado passa pelas Exposições de Motivo (daqui por diante, E.M.) Ao exporem seus motivos, os ministros revelaram quais as prioridades, o que entendem como demandas, quais as formas de equacioná-las; em suma, a orientação política com a qual coordenam sua pasta e também como esta se relaciona com a orientação geral do governo.

Ao me deparar com as E.M. fiquei convencido que estes documentos estavam mais próximos dos propósitos desta investigação. As E.M. expressam a comunicação entre o planejamento e a execução, estão na imediata interface entre ambos. Elas são algo mais palpável que os planejamentos que se fazem periodicamente baseados em intenções, ou os discursos e escritos que idealmente tratam do que é e do que deveria ser feito. Ao mesmo tempo, são mais abstratas, mais próximas do nível teórico do que um inventário de obras, ou um orçamento de gastos e investimentos; seria a forma mais concreta dos planos de ação de governamentalização. Dadas estas possibilidades, optei por tomar definitivamente as E.M. como base de análise e abandonar o esforço feito até então, que não havia surtido efeitos maiores, considerando a qualidade e a dispersão do material, como já observado. Outras escolhas metodológicas precisaram ser feitas diante desse material, como extrair dele as respostas às perguntas que eu carregava?

4 As E.M. do MINTER estão organizadas em brochuras por ano e distribuídas em pastas. Para cada ano há cadernos suplementares distribuídos por setores (pessoal, organização, administração geral, obras e orçamento) replicando os documentos arquivados no caderno geral. Têm um formato padrão: cabeçalho com a data, lugar e identificação da E.M.; cumprimento respeitoso ao presidente; o texto expondo os argumentos; cumprimento formal e assinatura do ministro. 0 tamanho era variável, entre uma lauda até cinquenta ou sessenta, mas a maioria tinha entre duas e três. Os conteúdos também eram diversos, tratavam de questões relativas ao funcionalismo, de obras e compra de equipamentos, anteprojetos de lei, demandas orçamentários, pedidos de isenção fiscal, relatórios ministeriais, prestação de contas e coisas afins. ${ }^{16}$

O material, tomado em conjunto, tinha algumas vantagens evidentes. A primeira delas é a anteriormente explicitada, a natureza do documento, que permite ao analista observar o propósito do ministério, suas intenções e sentidos; mas sem assumi-los em um nível demasiadamente abstrato. Outro ponto positivo é o fato deles estarem dispostos de maneira seriada e numerada. Isto me ofereceu um conjunto unitário, uma sequência segura, sem lacunas. As lacunas e a falta de sequência tinham me parecido um grande empecilho na primeira base pesquisada, pois dificultava seguir as recomendações de Perla Zusman (op.cit.) e evitar reproduzir uma visão parcial dos documentos, cuja parcela visível poderia ser exatamente aquela que o sujeito produtor do documento ou o organizador quis evidenciar; ou então mero acidente, nunca se poderia saber. Também para evitar reproduzir a intenção dos produtores dos 
documentos, optei por me debruçar sobre os cadernos principais, com todas as E.M., descartando os cadernos temáticos, o que totalizou mil cento e sessenta documentos no intervalo entre oito de julho de 1964 e vinte e sete de janeiro de 1969.

Desenvolvi a análise dos documentos lendo-os individual e integralmente. Sistematizeios em um quadro sintético a partir da sua finalidade (orçamento, institucionalização, isenções fiscais, funcionalismo, etc.) procedências (órgão interessado), descrição do conteúdo e observações suplementares, quando relevantes. Este quadro ofereceu uma visão geral sobre o processo em análise. Esta organização me permitiu ainda tomar o universo documental em seus aspectos tanto de conjunto quanto individualmente, quando havia algo substantivo explicitado.

A visão do conjunto associada aos conteúdos individuais dos documentos mais substantivos me permitiu buscar as respostas às minhas perguntas com mais segurança, possibilitou que acompanhasse os planos de ação no cotidiano do ministério, defrontado com as dificuldades e possibilidades impostas, como restrições orçamentárias, desacordos com outros setores do governo ou alterações nos planos iniciais. Enfim, foi possível, a partir daí, verificar a operacionalização dos planos de governo em planos de ação de governamentalização propriamente ditos.

Além das E.M., vali-me também de documentos consultados em outras fontes. Valioso foi o arquivo pessoal de Cordeiro de Farias disponível no arquivo do CPDOC/FGV no Rio de Janeiro. Nesta base encontrei pronunciamentos e impressões pessoais do ex-ministro do MECOR sobre sua própria atuação e o sentido que procurou imprimir ao ministério que ele conduzia. A base documental que está sendo montada pelo programa "Memórias Reveladas", também do Arquivo Nacional, foi aproveitada sobretudo pelos documentos relativos a Albuquerque e Lima. Alguns desses documentos estão disponíveis na internet, outros estão digitalizados mas só podem ser consultados nas sedes do Arquivo Nacional (de Brasília e do Rio de Janeiro), outros não estão digitalizados. Utilizei ainda memórias, depoimentos e textos de autoria dos ministros envolvidos, assim como de pessoas relacionadas diretamente com a institucionalização do MINTER.

\section{Considerações finais}

Conforme dito, procurei neste texto compartilhar uma experiência de pesquisa em seus detalhes mais práticos, derivados e substantivados a partir de uma reflexão teórica e metodológica. Espero com isso debater as minhas opções e possibilidades com o(a)s demais colegas, a fim de aprimorar a pesquisa em arquivos nos campos da Historia da Geografia e da Geografia Histórica.

Gostaria de ressaltar as dificuldades por mim encontradas ao longo da trajetória acima exposta enquanto fragilidades a serem revistas nas práticas de pesquisa de geógrafo(a)s em geral. 0 primeiro deles é própria delimitação dos campos de estudos internos à Geografia e no seu diálogo com formações disciplinares afins. As delimitações entre Geografia Histórica e História da Geografia me pareceram demasiadamente arbitrária. Felizmente pude me deparar com uma bibliografia muito avançada neste sentido, destacaria os trabalhos de Perla Zusman (op.cit.), Manoel Fernandes Sousa Neto (2012), Vincent Berdoulay (2008) e Félix Driver (1992). 
De outra feita, senti uma clara necessidade de debatermos com mais sistematicidade o uso de arquivos históricos enquanto fontes de pesquisa, sobretudo na esfera da Geografia que está em interface direta com a História. Acredito que ainda prevalece na Geografia certa concepção ingênua sobre os arquivos, o que nos leva e esperar deles respostas prontas, objetivas e claras. Ficou bastante claro para mim que, muito pelo contrário, é preciso muito zelo na formulação das perguntas que nos levam ao arquivo; são as perguntas que falam por nós, e não os documentos previamente dispostos. Somase a isso certa ansiedade do geógrafo diante de arquivos imensos, aparentemente impenetráveis e inesgotáveis. Neste quesito, contei com a valiosa contribuição de minha orientadora, com bastante trânsito pela antropologia, ela me ensinou a ter mais cuidado com o Arquivo. Valioso também foi o trabalho de Antônio Carlos de Souza Lima (op. cit.) e Perla Zusman (op.cit.).

\section{BIBLIOGRAFIA}

Berdoulay, V. (1981). The contextual approach. In: Stoddart, D.R. (ed.). Geography, ideology and social concern. Oxford: Blacwell, pp. 8-16.

(2007). o poder simbólico. $11^{\mathrm{a}}$ ed. Rio de Janeiro: Bertrand Brasil.

(2008). La formation de l'école française de géographie. $3^{\mathrm{a} e d . ~ P a r i s: ~ E ́ d i t i o n s ~ d u ~ C T H S . ~}$

BRASIL. Manual de Redação da Presidência da República. Disponível em: http://www.planalto.gov.br/ ccivil_03/manual/manual.htm\#_Toc26002107. Acesso em: 08/07/2014.

Brenner, N. (2001). The limits to scale? Methodological reflections on scalar structuration. Progress in Human Geography, vol. 25, n. 4, pp. 591-614.

Driver, F. (1992). Geography's of empire: histories of geographical knowledge. Environment and planning D: Society and space, vol. 10, n.1, pp. 23-40.

Escolar, M. (1996). Crítica do discurso geográfico. São Paulo: Edusp.

FArias, O. C. de (2001). Diálogo com Cordeiro de Farias: meio século de combate. Rio de Janeiro: Biblioteca do Exército Editora.

Foucault, M. (1981). Microfísica do Poder. $2^{\mathrm{a}}$ ed. Rio de Janeiro: Graal.

Gomes, P. C. da C. (2006). Geografia fin-de-siècle: o discurso sobre a ordem espacial do mundo e o fim das ilusões. In.: CASTRO, I.E, de; GOMES, P. C. da C; CORRÊA, R. L. (org.). Explorações Geográficas: percursos no fim do século. $2^{2}$ ed. Rio de Janeiro: Bertrand Brasil, pp. 13-42.

Howitt, R. (2008). Scale. In: AGNEW, J.; MITCHELL, K.; TOAL, G. (Ed.). A Companion to Political Geography. Maalden (USA), Oxford (UK): Blackwell, pp.138-156.

Iorio, G. S. (2007). Ideologias Geográficas sob Regime Militar no Brasil: O Ministério do Interior (1974-1980). Monografia. Departamento de Artes e Humanidades, Universidade Federal de Viçosa, Viçosa-MG.. 
Lima, A. C. de S. (1995). Um grande cerco de paz: Poder tutelar, indianidade e formação do Estado no Brasil. Petrópolis: Vozes.

Marston, S. A. (2000). The social construction of scale. Progress in Human Geography, vol. 24, n. 2, pp. 219-242,

Moraes, A. C. R. (2000). Bases da formação territorial do Brasil: o território colonial brasileiro no "longo" século XVI. São Paulo: HUCITEC.

Harvey, D. (1990). Between Space and Time: Reflections on the Geographical Imagination. Annals of the Association of American Geographers, vol. 80, n. 3, pp. 418-434.

Souza Neto, M. F. de (2012). Planos para o Império: os planos de viação do Segundo Reinado (1869-1889). São Paulo: Alameda.

Torres, S. M. (1989). A experiência do MINTER no controle e preservação de suas publicações oficiais. Revista de Biblioteconomia. Brasília, vol. 2, n.17.

ZUSMAN, P. B. (2000). Tierras para el Rey. Tres fronteras y la construcción del territorio del Río de La Plata (1750-1790). Tese de Doutorado (Geografia). Departament de Geografía, Universitat Autònoma de Barcelona. Bellaterra.

\section{Arquivos}

AN - Arquivo Nacional, Rio de Janeiro

Fontes

1- Documentos

ARQUIVO NACIONAL (2000). Catálogo dos documentos cartográficos do fundo Ministério do Interior. Rio de Janeiro. p. dig. (CODAC/SDC 004). Disponível em:<http://www.an.gov.br/sian/Multinivel/ Exibe_Pesquisa.asp?v_CodReferencia_ID=1118>.

\section{2- Legislação}

BRASIL. Lei no 4344 de 21 de junho de 1964. Disponível em <http://legis.senado.gov.br/legislacao/ ListaPublicacoes.action?id=114874\&tipoDocumento=LEI\&tipoTexto=PUB>. Acesso em 21/11/2012. (a)

BRASIL. Decreto $n^{\circ} 54026$ de 17 de julho de 1964. Disponível em:<http://www2.camara.leg.br/legin/ fed/decret/1960-1969/decreto-54026-17-julho-1964-394007-publicacaooriginal-1-pe.html> Acesso em 21/11/2012. (b)

BRASIL. Decreto-lei no 200 de 25 de fevereiro de 1967. Disponível em: <http://www.lex.com.br/ coletanea/default.aspx>. Acesso em 28/06/2007.

BRASIL. Decreto $n^{\circ} 66.882$ de 16 de julho de 1970. Disponível em: <http://www2.camara.leg.br/legin/ fed/decret/1970-1979/decreto-66882-16-julho-1970-408321-publicacaooriginal-1-pe.html>. Acesso em 21/11/2012.

\section{NOTAS}

1. Agradeço a orientação dedicada da $\operatorname{Prof}^{\mathrm{a}} \operatorname{Dr}^{\mathrm{a}}$ Ana Maria Daou e as contribuições dos professores Lia Osório Machado, Sérgio Nunes Pereira, Antonio Carlos de Souza Lima, Manoel Fernandes de Sousa Neto e Gisela Aquino Rio, integrantes da banca avaliadora. Gostaria de expressar também minha gratidão ao Conselho Nacional de desenvolvimento Científico e Tecnológico (CNPq) pelo financiamento concedido. 
2. São eles: “a) Superintendência do Plano de Valorização Econômica da Amazônia; b) Superintendência do Plano de Valorização Econômica da Fronteira Sudoeste do País; c) Superintendência do Desenvolvimento do Nordeste; d) Comissão do Vale do São Francisco; e) Instituto Brasileiro de Geografia e Estatística; f) Fundação Brasil Central; g) Administração dos Territórios Federais; h) Serviço Nacional de Municípios; i) Comissão de Desenvolvimento do Centro Oeste; j) Comissão Especial de Faixa de Fronteiras; l) Parque Nacional do Xingu." (BRASIL, 1964a).

3. Ainda que a maioria dos bancos regionais que passam a compor a estrutura administrativa do MINTER tivessem sido inaugurados anteriormente, suas finalidades e funcionalidades são reconfiguradas a partir de um programa maior de desenvolvimento (Iorio, 2015).

4. Emprego o termo "discurso geográfico" de forma genérica e maleável, sem preocupação nem intenção de referência a um conceito estável e bem delimitado. Para este debate, ver Escolar (1996) e Moraes (2002).

5. O trabalho de Zusman (op.cit.) sobre a fronteira é bastante ilustrativo neste sentido: "Las prácticas materiales y discursivas respecto de la frontera se producen sobre las prácticas materiales y discursivas del outro. Geografías materiales, discursivas, imaginadas, se yuxtaponen en la definición política de la frontera". (As práticas materiais e discursivas sobre a fronteira se produzem sobre as práticas materiais e discursivas do outro. Geografias materiais, discursivas, imaginadas, se justapõem na definição política da fronteira [Tradução Livre]) (Zusman,op cit.:46). 6. Tradução livre. No original: "Broadening the scope of the critical history of geography during the age of empire would allow us to consider more directly the cultural and political dimensions of geographical knowledge during this period. This is not necessarily to abandon a materialist approach; the development of 'knowledge' would instead be grasped as a situated social practice rather than a spontaneous reflex of the imperatives of economic development".

7. "O campo político é o lugar em que se geram, na concorrência entre os agentes em que nele se acham envolvidos, produtos políticos, problemas, programas, análises, comentários, conceitos, acontecimentos, entre os quais os cidadãos comuns, reduzidos ao estatuto de 'consumidores', devem escolher, com probabilidades de mal-entendidos tanto maiores quanto mais afastados estão do lugar de produção" (Bourdieu, 2007: 164).

8. Segundo Foucault (1981): "O que é importante para nossa modernidade, para nossa atualidade, não é tanto a estatização da sociedade mas o que chamaria de governamentalização do Estado" (p.292).

9. Há uma ampla e profícua bibliografia que reflete sobre a construção social da escala, no entanto não cabe nas finalidades deste texto explorá-la. Para ver duas bos sínteses críticas e propositivas do debate, ver Marston (2000) e Howitt (2008).

10. "Pero también podríamos preguntarnos si este interés por la reconstrucción histórica no supone, de manera contraria entonces, la necesidad actual de que el pasado se inmiscuya en nuestro presente." (Mas também poderíamos perguntar se este interesse pela reconstrução histórica não supõe, de maneira contrária então, à necessidade atual de que o passado se imiscua em nosso presente (Zusman, op cit.:106, tradução livre).

11. "É importante salientar que o controle e a preservação da produção documentária do MINTER sempre se constituiu numa grande preocupação para a Coordenadoria de Documentação - COD. Já em 1977, sua programação incluía projetos voltados para esses aspectos. Haja visto o Projeto do Módulo Documentos Oficiais do Sistem Eu. (sic) Documentação do Ministério do Interior, que definiu a política de identilicaçao (sic), reunião, controle, normalização, tratamento técnico, distribuição e disseminação de seus documentos oficiais”(Torres, 1989: 188).

12. Segundo o site do programa: "O Centro de Referência das Lutas Políticas no Brasil, denominado "Memórias Reveladas", foi institucionalizado pela Casa Civil da Presidência da República e implantado no Arquivo Nacional com a finalidade de reunir informações sobre os fatos da história política recente do País. 
Dando continuidade a iniciativas dos últimos governos democráticos, em novembro de 2005, o Presidente Lula assinou decreto regulamentando a transferência para o Arquivo Nacional dos acervos dos extintos Conselho de Segurança Nacional, Comissão Geral de Investigações e Serviço Nacional de Informações, até então sob custódia da Agência Brasileira de Inteligência (Abin) e passou à Casa Civil a coordenação do recolhimento dos arquivos. O Centro constitui um marco na democratização do acesso à informação e se insere no contexto das comemorações dos 60 anos da Declaração Universal dos Direitos Humanos. Um pedaço de nossa história estava nos porões. 0 'Memórias Reveladas' coloca à disposição de todos os brasileiros os arquivos sobre o período entre as décadas de 1960 e 1980 e das lutas de resistência à ditadura militar, quando imperaram no País censura, violação dos direitos políticos, prisões, torturas e mortes. Trata-se de fazer valer o direito à verdade e à memória." [http://www.memoriasreveladas.gov.br/]

13. Nas outras vezes em que estive no Arquivo Nacional de Brasília não notei a presença desses pesquisadores, não sei dizer com exatidão se estavam lá ou não.

14. A funcionária chama-se Deyse, a quem agradeço fortemente.

15. As CCMI's eram comissões cuja finalidade era a de criar um espaço de interlocução entre as diferentes esferas do MINTER com apresentações dos chefes do gabinete do ministro e dos órgãos subordinados, os encontros ocorriam duas vezes ao ano, a partir de 1971. Tinha conhecimento prévio da existência destas Comissões pelo trabalho que já vinha desenvolvendo sobre o MINTER e a revista Interior (Iorio, 2010) e desde então busquei insistentemente informações sobre ela na primeira base de dados, em vão.

16. Os documentos foram organizados em tabelas que estão expostas nos capítulos três e quatro.

\section{RESUMOS}

O presente texto é um relato de pesquisa realizada como tese de doutoramento no âmbito no Programa de Pós Graduação em Geografia da Universidade Federal do Rio de Janeiro. No decorrer da pesquisa algumas questões de ordem teórico-metodológica se impuseram, duas delas estão destacadas aqui: i) o problema teórico da relação entre a história da geografia e geografia histórica e como este se traduz em uma questão metodológica de primeira importância; ii) o cuidado necessário que requer a lida com as fontes, para que não haja contradição entre a base teórica e os procedimentos práticos da pesquisa.

El presente texto es un relato de la investigación realizada como tesis de doctorado en el ámbito del Programa de Posgrado en Geografía de la Universidad Federal de Río de Janeiro. A lo largo de la investogación algunas cuestiones de órden teórico-metodológico se impusieron, dos de ellas están destacadas aquí: i) el problema teórico de la relación entre la historia de la geografía y la geografía histórica y como este se traduce en una cuestión metodológica de primera importancia; ii) el cuidado necesario que requiere el tratamiento de las fuentes, para que no haya contradicción entre la base teórica y los procedimientos prácticos de la investigación.

This text is an account of a research carried out as a $\mathrm{PhD}$ thesis within the Postgraduate Program in Geography of the Federal University of Rio de Janeiro. In the course of the research some theoretical and methodological questions were imposed, two of them are highlighted here: i) the theoretical problem of the relationship between the history of geography and historical geography and how this implies in a methodological question of first relevance; ii) the necessary 
care it requires to deal with the sources, so that there is no contradiction between the theoretical basis and the practical procedures of the research.

Ce texte est un rapport de recherche réalisé sous la forme d'une thèse de doctorat au sein du programme de troisième cycle en géographie de l'Université Fédérale de Rio de Janeiro. Au cours de la recherche, quelques questions théoriques et méthodologiques ont été posées, dont deux sont soulignées ici: i) le problème théorique de la relation entre histoire de la géographie et géographie historique et comment cela se traduit par une question méthodologique de première importance; ii) le soin nécessaire qui l'oblige à traiter avec les sources, de sorte qu'y ait pas de contradiction entre la base théorique et les procédures pratiques de la recherche.

ÍNDICE

Índice geográfico: Brasil

Palavras-chave: história da geografia (metodologia), geografia histórica (metodologia), pesquisa em arquivo

Palabras claves: historia de la geografía (metodología), geografia histórica (metodología), trabajo de archivo

Índice cronológico: 1964-1970

Keywords: history of geography (methodology), historical geography (methodology), archive research

Mots-clés: histoire de la géographie (méthodologie), géographie historique (méthodologie), recherche d'archive

\section{AUTOR}

\section{GUSTAVO SOARES IORIO}

Professor do Departamento de Geografia da Universidade Federal de Viçosa 